\title{
The effectiveness of chest radiography in the diagnosis of pediatric COVID-19
}

\author{
Sinem Oral Cebeci ${ }^{1}$, Hasret Ayyıldız Civan², Figen Palabıyık ${ }^{3}$, Ilyas Tolga Erkum ${ }^{4}$, Nevin Hatipoğlu \\ Sami Hatipoğlu ${ }^{4}$
}

${ }^{1}$ Department of Pediatric Emergency, Cerrahpasa Faculty of Medicine, Istanbul University-Cerrahpasa, Istanbul

${ }^{2}$ Department of Pediatric Gastroenterology, Hepatology and Nutrition, Istanbul Bakirkoy Dr Sadi Konuk Training and Research Hospital, Istanbul

${ }^{3}$ Department of Pediatric Radiology, Istanbul Bakirkoy Dr Sadi Konuk Training and Research Hospital, Istanbul

${ }^{4}$ Department of Pediatrics, Istanbul Bakirkoy Dr Sadi Konuk Training and Research Hospital, Istanbul

${ }^{5}$ Department of Pediatric Infections, Istanbul Bakirkoy Dr Sadi Konuk Training and Research Hospital, Istanbul

Received: 2021-01-06.

Accepted: 2021-02-15

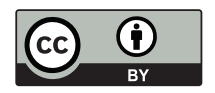

This work is licensed under a Creative Commons Attribution 4.0 International License

J Clin Med Kaz 2021; 18(2):20-24

Corresponding author:

Sinem Oral Cebeci.

E-mail: sinemoralcebeci@hotmail.com

\section{Abstract}

Objectives: To determine the correlation between the PCR results and chest radiography findings of pediatric patients who were applied to pediatric emergency department with a suspicion of COVID-19 infection.

Material and methods: A single-center retrospective single-blind study of patients who presented at the pediatric emergency department between 20.03.2020-15.04.2020. Patients with suspected COVID-19 infection were examined by nasopharyngeal and oropharyngeal swabs, PCR and posteroanterior chest radiographs. According to the PCR results, patients were divided into 2 groups as with (group 1) and without COVID 19 (group 2). All posteroanterior chest radiographs were evaluated by an experienced pediatric radiologist who did not know the PCR results.

Results: 167 patients were included in the study. Eighty (47.9\%) of patients were female and 87 (52.1\%) were male. The mean age was $8.6 \pm 4.85$ (1 month-16 years). The most common complaints were fever (\%34.7) and cough (\%54.5). 50 (32.9\%) patients had an exposure history, 15 (9\%) had a suspicious exposure history, and 102 (61.1\%) had a history of exposure with a PCR proven COVID-19 patient. In patients with a contact to a COVID-19 patient, the most common source of infection was parents (65.7\%). Out of 167 patients, 44 (26.3\%) were PCR positive (group 1) and 123 (73.7\%) were negative (group 2). 13 (29.5\%) patients in group 1 and 14 (11.4\%) patients in group 2 had findings on posteroanterior chest radiography. Among patients with signs on chest radiography (27 patients); eighteen (66.7\%) patients had unilateral and 9 (33.3\%) patients had bilateral lesion. In 15 (55.6\%) of the cases, the finding was in single focus and in 12 (44.4\%) there were multiple foci.

Posteroanterior chest radiography findings were statistically significantly higher in group 1 compared to group $2(p=0.008)$. There was no significant difference between the two groups in terms of bilateral lesion frequency and multi-focal presence (respectively, $p=0,245$, $\mathrm{p}=0,518)$. Unilateral lung findings were higher in group 1 compared to group $2(p=0,023)$. The incidence of single focus was higher in the group $1(20.4 \%)$ than group 2 (4.8\%), ( $p=0,004)$.

Conclusion: Posteroanterior chest radiography which is widely used in all pediatric emergencies may help to diagnose COVID-19 patients with low dose radiation exposure. And this will help in rapid diagnosis and prevent unnecessary CT imaging in pediatric age group.

Key words: pediatric COVID-19, diagnostic imaging, imaging features, chest radiographs, coronavirus

\section{Introduction}

COVID-19 is a new disease caused by the SARSCoV-2 virus, that induce pandemic in early 2020 with high mortality and morbidity worldwide $[1,2]$.
COVID-19 infection was thought to be very rare in children during the onset of pandemic. However, rise in number of adult cases overtime caused increased transmission to children. According to Centers for Disease 
Control and Prevention (CDC) data $11,1 \%$ of COVID-19 patients diagnosed until 27th January 2021 were under the age of 18 [3].

The virus can be transmitted from symptomatic or asymptomatic individuals. The main route of transmission is droplet, but it can also be transmitted by contact or from the gastrointestinal tract [4]. The incubation period of the virus is 5-6 days (average 2-14 days) [5-7]. Accurate diagnosis is made by real-time reverse transcription polymerase chain reaction (rRTPCR) test by determining specific sequences of virus RNA from nasopharyngeal/oropharyngeal swab, endotracheal aspirate, or bronchoalveolar lavage.

Normal or decreased leukocyte, decreased neutrophil and lymphocyte count, increased D-Dimer and / or LDH levels can be detected during the course of the disease but there is no specific laboratory findings for the disease $[7,8]$.

During pandemic, clinicians try to make the most accurate and rapid diagnosis in order to provide appropriate treatment to the affected patients and prevent the spread of the disease. It takes time to complete molecular investigations which makes rapid diagnosis difficult. Computed tomography (CT) imaging was frequently used for the diagnosis of the disease in the literature [9-11]. Although CT has a high sensitivity (56$91 \%$ ) in detecting chest pathology, its use is not recommended especially in pediatric patients due to high radiation exposure. In addition, outpatient use is limited due to cost burden and practical issues (eg sterilization after use) [12-15]. Therefore, chest radiography is also important because it contains low dose radiation, relatively cheaper and widely available imaging method in pediatric emergency departments. It has been reported that chest radiography was used as a first step triage tool until the molecular diagnosis was made in Italy and England hospitals $[16,17]$. However, there are limited number of studies on the contribution of chest radiography to diagnosis in patients with suspected COVID-19 diagnosis in the pediatric age group.

In this study, we aimed to report the distribution of the abnormal radiological findings in PCR positive cases and to determine the correlation between the PCR results and chest radiography findings in patients who were applied to the pediatric emergency department with the suspicion of COVID-19.

\section{Material and methods}

The study was as a single-center retrospective singleblind study. Medical records of patients who were admitted to Istanbul Bakirkoy Dr Sadi Konuk Training and Research Hospital Pediatric Emergency Department between 20.03.202015.04.2020 were reviewed retrospectively. The study included: 1. Patients with a household member a) who have admitted to the hospital with a diagnosis of respiratory tract infection within the last 14 days or b) who had COVID-19 diagnosis or c) who had fever and cough or had respiratory distress with/without fever, 2. Patients with a history of exposure to an individual who was diagnosed with COVID-19, 3. Patients with cough and/or fever of $\geq 38^{\circ} \mathrm{C}$ and/or positive respiratory examination findings and/ or tachypnea and/or oxygen saturation $<92 \%$ in the room air.

All patients underwent posteroanterior (PA) chest radiography. Nasopharyngeal and oropharyngeal swab samples were evaluated by PCR for accurate diagnosis. According to the PCR results, patients were divided into 2 groups as patients with (group 1) and without (group 2) COVID-19. All of the PA chest radiographs were evaluated by a single experienced (10 years) pediatric radiologist who was blind to the PCR results. Radiographic features, laterality (unilateral / bilateral), focality (focal / multifocal) and location were evaluated. Relationship between the chest radiology features and COVID-19 were evaluated, and distribution of abnormal radiological findings detected in PCR positive cases were reported.

\section{Statistical analysis}

IBM SPSS (IBM Statistical Program for Social Sciences, Armonk, NY, USA Windows. 23.0) was used for statistical analyzes. The distribution of the data was examined by the Shapiro Wilk test. The categorical variables were expressed as n (\%). The continuous variables with normal distribution were presented as mean \pm standard deviation (SD). Pearson's chisquare test was used for comparing the categorical variables between group 1 and group 2 . The comparison of the mean age of group 1 and group 2 was performed by Independent Samples $\mathrm{t}$ Test. The results were evaluated at the significance level of $\mathrm{p}$ $<0.05$, in the $95 \%$ confidence interval.

\section{Results}

167 patients were included in the study. Eighty (47.9\%) of the patients were female and $87(52.1 \%)$ were male. The mean age was $8.6 \pm 4.85$ ( 4 months -16 years). According to the age groups; $15(8.9 \%)$ patients were under 2 years of age, 39 (23.4\%) patients were between 2-5 years, 43 (25.7\%) patients were between $5-10$ years of age and $70(41.9 \%)$ patients were older than 10 years of age (Table 1).

Table $1 \quad$ Patient characteristics and symptoms

\begin{tabular}{|c|c|c|}
\hline & $\begin{array}{l}\text { Group } 1 \\
n=44\end{array}$ & $\begin{array}{l}\text { Group } 2 \\
n=123\end{array}$ \\
\hline & $\mathrm{n}(\%)$ & $\mathrm{n}(\%)$ \\
\hline \multicolumn{3}{|l|}{ Gender } \\
\hline Female & $24(54,5 \%)$ & $56(45,5 \%)$ \\
\hline Male & $20(45,5 \%)$ & $67(54,5 \%)$ \\
\hline \multicolumn{3}{|l|}{ Age (years) } \\
\hline$<2$ & $2(4,5 \%)$ & $13(10,6 \%)$ \\
\hline $2-5$ & $10(22,7 \%)$ & $29(23,6 \%)$ \\
\hline $5-10$ & $9(20,5 \%)$ & $34(27,6 \%)$ \\
\hline$>10$ & $23(52,3 \%)$ & $47(38,2 \%)$ \\
\hline \multicolumn{3}{|l|}{ Exposure History } \\
\hline Positive & $28(63,6 \%)$ & $74(60,2 \%)$ \\
\hline Unknown & $10(22,7 \%)$ & $5(4,1 \%)$ \\
\hline Negative & $6(13,7 \%)$ & $44(35,8 \%)$ \\
\hline \multicolumn{3}{|l|}{ Symptoms } \\
\hline Fever & $18(40,9 \%)$ & $40(32,5 \%)$ \\
\hline Cough & $25(56,8 \%)$ & $66(53,7 \%)$ \\
\hline Nausea-Vomit & $1(2,3 \%)$ & $5(4,1 \%)$ \\
\hline Diarrhea & $2(4,5 \%)$ & $3(2,4 \%)$ \\
\hline Weakness & $1(2,3 \%)$ & $3(2,4 \%)$ \\
\hline Decreased sense of smell/taste & $3(6,8 \%)$ & $1(0,8 \%)$ \\
\hline Others & $4(9,1 \%)$ & $4(3,3 \%)$ \\
\hline
\end{tabular}

Most common complaints were fever in 58 (34.7\%) patients and cough in 91 (54.5\%). Nausea- vomiting (3.6\%), diarrhea $(3 \%)$, weakness $(2.4 \%)$, decreased sense of smell and taste $(2.4 \%)$ were also other determined complaints (Table 1$)$.

Out of 167 patients; 50 (32.9\%) patients had no exposure history with a COVID-19 patient, 15 (9\%) had a unknown exposure history, and $102(61.1 \%)$ had a history of exposure with a PCR-proven COVID-19 patient (Table 1). For patients who had an exposure to a COVID-19 case; the most common source of infection was father in $39(38.2 \%)$ patients, mother in $18(11.8 \%)$, both parents in $16(15.7 \%)$, non-parent relatives in $24(23.5 \%)$, community in $5(4.9 \%)$. 
Radiological findings were found positive in 27 (16.2\%) out of 167 patients. $18(66.7 \%)$ patients had unilateral and 9 $(33.3 \%)$ patients had bilateral involvement. In $15(55.6 \%)$ of the cases, finding was foci and in 12 (44.4\%) multifocal. For unilateral and unifocal cases; lesion was found at right lower lobe in $8(29.6 \%)$, patients at left lower lobe in $4(14.8 \%)$ patients, at right middle lobe in $2(7.4 \%)$ patients and at left middle lobe in 1 (3.7\%) patient. For unilateral and multifocal cases; lesions were found in right middle and lower lobe in $2(7.4 \%)$ patients, left middle and lower lobe in $1(3.7 \%)$ patients. The most common localization in bilateral cases were the right and left lower lobe in $5(18.5 \%)$ cases. None of the patients had pleural effusion and lymphadenopathy.

Table 2 Imaging findings of the patients

\begin{tabular}{|l|l|l|l|l|}
\hline \multicolumn{2}{|c|}{} & $\begin{array}{l}\text { Group 1 } \\
\text { n=44 }\end{array}$ & $\begin{array}{l}\text { Group 2 } \\
\text { n=123 }\end{array}$ & p \\
\hline \multicolumn{2}{|c|}{} & $\mathrm{n} /(\%)$ & $\mathrm{n} /(\%)$ & \\
\hline Positive Features & $13(29,5 \%)$ & $14(11,4 \%)$ & 0,008 & \\
\hline \multirow{2}{*}{ Laterality } & Unilateral & $9(20,5 \%)$ & $9(7,3 \%)$ & 0,023 \\
\cline { 2 - 5 } & Bilateral & $4(9 \%)$ & $5(4,1 \%)$ & 0,245 \\
\hline & Focal & $9(20,5 \%)$ & $6(4,9 \%)$ & 0,004 \\
\cline { 2 - 5 } & Multifocal & $4(9 \%)$ & $8(6,5 \%)$ & 0,518 \\
\hline
\end{tabular}

Of the 167 patients, PCR test was positive (group 1) in 44 (26.3\%) patients and negative in (group 2) 123 (73.7\%). There was no difference in mean age and gender between the two groups ( $\mathrm{p}=0,098$ and $\mathrm{p}=0,38$, respectively). 13 (29.5\%) patients in group 1 and $14(11.4 \%)$ patients in group 2 had radiological features in PA chest radiography. The presence of findings on PA chest radiography was statistically significantly higher in group 1 compared to group $2(\mathrm{p}=0.008)$. The rate of detecting findings on chest radiography was 2.59 times higher in PCR positive ones than negative ones (95\% CI, 1.32-5.08). There was no significant difference between the two groups in terms of bilateral lesion frequency and multi-focal lesions $(\mathrm{p}=0,245$, $\mathrm{p}=0,518$, respectively).

Unilateral chest finding was found in $9(20.4 \%)$ patients in group 1 and $9(7.3 \%)$ in group 2, and it was statistically significantly higher $(\mathrm{p}=0,023)$ in PCR positive group. Focal lesion was found significantly higher in the group 1 compared to group $2(p=0,004)$ (Table 2$)$. When the lesions are evaluated according to their location, 2 patients have lesion in the middle and 7 patients in the lower lobe in group 1 and 1 patient and 5 patients respectively in group 2 .

\section{Discussion}

COVID-19 caused a widespread infection and public health problem globally. Over 100 million infected patients and over 2 million deaths due to this infection have been reported until the 27 th of January. Compared to adult patients; the frequency and mortality of COVID-19 in children are very low. In US 11,1\% of all COVID- 19 cases and $<0,2 \%$ of all COVID- 19 deaths are under age of 18 [3].

According to the United States Disease Protection and Control Centers COVID-19 study group, about a one third of patients in the pediatric age group are between 15 and 18 years old. Other age groups distributions were; $27 \%$ was between 10 14 years, $15 \%$ was between $5-9$ years, $11 \%$ was between $1-4$ years, and $15 \%$ was younger than 1 year old [18]. Similar to this study, more than half of our PCR positive cases are older than 10 years old and about a quarter of PCR positive children was found to be under 5 years old.
Symptoms experienced in children are similar to adults. But it must be keep in mind that $9-11 \%$ of infected children can be asymptomatic $[8,19]$. The most common symptoms in children are fever (44-50\%), cough (38\%), rhinitis (7.2\%), headache (28\%), nausea-vomiting (11\%), diarrhea (13\%), dyspnea (13\%) $[7,8,18,19]$. Giacomelli et al demonstrated that loss of taste and smell were detected in 53\% of their adult cases, and they suggested to add these symptoms into the diagnostic criterias especially in younger individuals [20]. The most common complaints in our COVID-19 patients were cough (56.8\%) and fever $(40.9 \%)$. Also $6.8 \%$ of our patients experienced loss of taste and smell. The difference between the loss of taste and smell rate can be explained with difficulty in expressing by children.

In pediatric age group, transmission from a household contact is $82 \%$ [8]. Centers for Disease Control and Prevention COVID-19 Response Team reported that transmission from a household contact to children was $91 \%$ [18]. Our study showed that $70 \%$ of our PCR positive patients had at least one of their parents had a diagnosis of COVID-19.

PA chest radiography is not routinely recommended due to low sensitivity in the early phases of COVID-19 infection [21]. Limited number of studies evaluating COVID-19 PA chest radiography findings in pediatric age group demonstrated similar radiological features with other coronavirus types of infections. In children, chest radiography generally reveals bilateral patchy airspace consolidations, peribronchial thickening and ground-glass opacity in the periphery of the lungs [22-27]. Pneumothorax, cavitation, lymphadenopathy are rarely found [28]. If pleural effusion, lung nodules, and lymphadenopathy are detected, bacterial infection should be considered as first diagnosis [29]. These findings in children are more unspecific and milder compared to those in adults [30].

Wong et al. evaluated 64 adult COVID-19 patient's chest radiographs at initial admission and found positive features in $51(80 \%)$ and reported that chest radiography had $69 \%$ sensitivity for any abnormal findings [12]. Yoon et al. found $56 \%$ positivity on chest radiography in their small case series [31]. In a study evaluating 636 ambulatory COVID-19 patients chest radiography, only $265(41.7 \%)$ of the patients had abnormal findings [32]. Besides to studies including adult patients, our study demonstrated $29.5 \%$ significant findings in chest radiographs in pediatric patients with the diagnosis of COVID-19 and it is significantly higher compared to PCR negative cases.

Wong et al described the most common radiographic COVID-19 findings as peripheral round consolidations, groundglass opacities and pulmonary nodules. Although the distribution of radiological findings may vary, it is more common bilaterally and in the lower lobules [12]. Weinstock et al reported $20.9 \%$ bilateral and, 24.2\% multifocal lesions in their study [32]. Even in asymptomatic patients, the disease can progress from unilateral focal lesion to a diffuse ground-glass opacities and consolidations [33]. Our study revealed that unilateral and unifocal chest findings were more common in the PCR positive group. In contrast to the literature, two groups in our study showed no significant difference for bilateral and multifocal lesion.

Pleural effusion was rarely detected in studies evaluating COVID-19 radiological findings and was generally associated with poor prognosis $[12,13]$. We have not detected any pleural effusion or lymphadenopathy among our cases.

In a case of COVID-19 infection, it is important to diagnose rapidly and initiate treatment early. We need ancillary methods for facilitating the diagnosis during the PCR turnaround 
processing times. In our country, imaging methods using high dose radiation such as $\mathrm{CT}$ is not recommended in suspicion of COVID-19 pediatric cases unless it is mandatory. For this reason, methods that are widely used with no restrictions in pediatric emergency departments and with relatively lower costs may help us for the diagnosis of COVID-19. Our study demonstrated that PA chest radiography may facilitate the COVID-19 diagnosis, which does not contain high dose radiation and is widely used in all pediatric emergencies. In conclusion, PA chest radiography can speed up the diagnosis until the PCR results are obtained and prevent unnecessary use of CT in pediatric age group.
Our study has some limitations precluding us from reaching strong conclusions. First, it is a single center study. The second limitation is the number of patients. It is insufficient to evaluate the difference between the chest radiographs of patients with and without COVID-19.

Disclosures: There is no conflict of interest for all authors.

Acknowledgements: None.

\section{References}

1. Guan WJ, Ni ZY, Hu Y, et al. Clinical characteristics of coronavirus disease 2019 in China. N Engl J Med. 2020; 382:1708-1720. https:// doi.org/10.1056/NEJMoa2002032

2. Wu C, Chen X, Cai Y, et al. Risk Factors Associated With Acute Respiratory Distress Syndrome and Death in Patients With Coronavirus Disease 2019 Pneumonia in Wuhan, China. JAMA Intern Med. Published online March 13, 2020. https://doi.org/10.1001/ jamainternmed.2020.0994

3. Demographic Trends of COVID-19 cases and deaths in the US reported to CDC. Retrieved from https://covid.cdc.gov/covid-datatracker/\#demographics

4. Riou J, Althaus CL. Pattern of early human-to-human transmission of Wuhan 2019 novel coronavirus (2019-nCoV), December 2019 to January 2020. Euro Surveill. 2020; 25:2000058. https://doi.org/10.2807/1560-7917.ES.2020.25.4.2000058

5. Wu JT, Leung K, Leung GM. Nowcasting and forecasting the potential domestic and international spread of the 2019-nCoV outbreak originating in Wuhan, China: a modelling study. Lancet. 2020; 395:689-697. https://doi.org/10.1016/S0140-6736(20)30260-9

6. Jiang X, Rayner S, Luo MH. Does SARS-CoV-2 has a longer incubation period than SARS and MERS?. J Med Virol. 2020; 92:476478. https://doi.org/10.1002/jmv.25708

7. Chen ZM, Fu JF, Shu Q, et al. Diagnosis and treatment recommendations for pediatric respiratory infection caused by the 2019 novel coronavirus [published online ahead of print, 2020 Feb 5]. World J Pediatr. 2020; 1-7. https://doi.org/10.1007/s12519-020-00345-5

8. Wang XF, Yuan J, Zheng YJ, et al. [Clinical and epidemiological characteristics of 34 children with 2019 novel coronavirus infection in Shenzhen]. Zhonghua Er Ke Za Zhi. 2020; 58:E008.

9. Chinese Society of Radiology. Radiological diagnosis of new coronavirus infected pneumonitis: Expert recommendation from the Chinese Society of Radiology (First edition). Chin J Radiol. 2020; 54: E001.

10. Zu ZY, Jiang MD, Xu PP, et al. Coronavirus Disease 2019 (COVID-19): A Perspective from China [published online ahead of print, 2020 Feb 21]. Radiology. 2020; 200490. https://doi.org/10.1148/radiol.2020200490

11. 11. Revel MP, Parkar AP, Prosch H, et al. COVID-19 patients and the radiology department - advice from the European Society of Radiology (ESR) and the European Society of Thoracic Imaging (ESTI) [published online ahead of print, 2020 Apr 20]. Eur Radiol. 2020; 1-7. https://doi.org/10.1007/s00330-020-06865-y

12. Wong HYF, Lam HYS, Fong AH, et al. Frequency and Distribution of Chest Radiographic Findings in COVID-19 Positive Patients [published online ahead of print, 2019 Mar 27]. Radiology. 2019; 201160.

13. $\mathrm{Xu} \mathrm{X,} \mathrm{Yu} \mathrm{C,} \mathrm{Qu} \mathrm{J,} \mathrm{et} \mathrm{al.} \mathrm{Imaging} \mathrm{and} \mathrm{clinical} \mathrm{features} \mathrm{of} \mathrm{patients} \mathrm{with} 2019$ novel coronavirus SARS-CoV-2. Eur J Nucl Med Mol Imaging. 2020; 47:1275-1280. https://doi.org/10.1007/s00259-020-04735-9

14. Ng MY, Lee EYP, Yang J, et al. Imaging profile of the COVID-19 infection: radiologic findings and literature review. Radiology. 2020; 2: e200034 https://doi.org/10.1148/ryct.2020200034

15. Bernheim A, Mei X, Huang M, et al. Chest CT Findings in Coronavirus Disease-19 (COVID-19): Relationship to Duration of Infection. Radiology. 2020; 295:200463. https://doi.org/10.1148/radiol.2020200463

16. 16. Lessons from the frontline of the covid-19 outbreak - The BMJ. Available at: https://blogs.bmj.com/bmj/2020/03/20/lessons-fromthe-frontline-of-the-covid-19- outbreak/?utm_campaign=shareaholic\&utm_medium=twitter\&utm_source=socialnetwork. Accessed March 20, 2020.

17. Imaging the coronavirus disease COVID-19. Available at: http://healthcare-ineuropa.com/en/news/imaging-the-coronavirus-diseasecovid-19.html. Accessed March 23, 2020.

18. CDC COVID-19 Response Team. Coronavirus Disease 2019 in Children - United States, February 12-April 2, 2020. MMWR Morb Mortal Wkly Rep. 2020; 69:422-426. https://doi.org/10.15585/mmwr.mm6914e4

19. Wei M, Yuan J, Liu Y, et al. Novel Coronavirus Infection in Hospitalized Infants Under 1 Year of Age in China. JAMA. 2020; 323(13):1313-1314. https://doi.org/10.1001/jama.2020.2131

20. Giacomelli A, Pezzati L, Conti F, et al. Self-reported olfactory and taste disorders in SARS-CoV-2 patients: a cross-sectional study [published online ahead of print, 2020 Mar 26]. Clin Infect Dis. 2020; ciaa330.

21. Yang W, Sirajuddin A, Zhang X, et al. The role of imaging in 2019 novel coronavirus pneumonia (COVID-19) [published online ahead of print, 2020 Apr 15]. Eur Radiol. 2020; 1-9. https://doi.org/10.1007/s00330-020-06827-4

22. Hon KL, Leung CW, Cheng WT, et al. Clinical presentations and outcome of severe acute respiratory syndrome in children. Lancet. 2003; 361:1701-1703. https://doi.org/10.1016/S0140-6736(03)13364-8

23. Chiu WK, Cheung PC, Ng KL, et al. Severe acute respiratory syndrome in children: experience in a regional hospital in Hong Kong. Pediatr Crit Care Med. 2003; 4:279-283. https://doi.org/10.1097/01.PCC.0000077079.42302.81

24. Bitnun A, Allen U, Heurter H, et al. Children hospitalized with severe acute respiratory syndrome-related illness in Toronto. Pediatrics. 2003; 112:e261. https://doi.org/10.1542/peds.112.4.e261 
25. Alfaraj SH, Al-Tawfiq JA, Altuwaijri TA, et al. Middle East respiratory syndrome coronavirus in pediatrics: a report of seven cases from Saudi Arabia. Front Med. 2019; 13:126-130. https://doi.org/10.1007/s11684-017-0603-y

26. Leung CW, Kwan YW, Ko PW, et al. Severe acute respiratory syndrome among children. Pediatrics. 2004; 113:e535-e543. https://doi. org/10.1542/peds.113.6.e535

27. Babyn PS, Chu WC, Tsou IY, et al. Severe acute respiratory syndrome (SARS): chest radiographic features in children. Pediatr Radiol. 2004; 34:47-58. https://doi.org/10.1007/s00247-003-1081-8

28. Hosseiny M, Kooraki S, Gholamrezanezhad A, et al. Radiology Perspective of Coronavirus Disease 2019 (COVID-19): Lessons From Severe Acute Respiratory Syndrome and Middle East Respiratory Syndrome. AJR Am J Roentgenol. 2020; 214:1078-1082. https://oi. org/10.2214/AJR.20.22969

29. Kanne JP, Little BP, Chung JH, et al. Essentials for Radiologists on COVID-19: An Update-Radiology Scientific Expert Panel [published online ahead of print, 2020 Feb 27]. Radiology. 2020; 200527.

30. Feng K, Yun YX, Wang XF, et al. Analysis of CT features of 15 children with 2019 novel coronavirus infection. Zhonghua Er Ke Za Zhi. 2020; 58:E007.

31. Yoon SH, Lee KH, Kim JY, et al. Chest Radiographic and CT Findings of the 2019 Novel Coronavirus Disease (COVID-19): Analysis of Nine Patients Treated in Korea. Korean J Radiol. 2020; 21:494-500. https://doi.org/10.3348/kjr.2020.0132

32. Weinstock MB, Echenique A, Russell JW, et al. Chest x-ray findings in 636 ambulatory patients with COVID-19 presenting to an urgent care center: a normal chest x-ray is no guarantee. J Urgent Care Med. 2020; 14:13-18.

33. Shi H, Han X, Jiang N, et al. Radiological findings from 81 patients with COVID-19 pneumonia in Wuhan, China: a descriptive study. Lancet Infect Dis. 2020; 20:425-434. https://doi.org/10.1016/S1473-3099(20)30086-4 